\title{
The Identity Theory of Powers Revised
}

\author{
Joaquim Giannotti ${ }^{1}$
}

Received: 1 December 2017 / Accepted: 5 April 2019 / Published online: 20 April 2019

(c) The Author(s) 2019

\begin{abstract}
Dispositionality and qualitativity are key notions to describe the world that we inhabit. Dispositionality is a matter of what a thing is disposed to do in certain circumstances. Qualitativity is a matter of how a thing is like. According to the Identity Theory of powers, every fundamental property is at once dispositional and qualitative, or a powerful quality. Canonically, the Identity Theory holds a contentious identity claim between a property's dispositionality and its qualitativity. In the literature, this view faces a contradiction objection that undermines its merits. We should therefore consider an alternative version that does not embrace the identity claim. My aim is to show that we can enjoy the benefits of the Identity Theory without embracing the identity between the dispositional and the qualitative. I shall argue that a distinction between two senses of dispositionality and qualitativity serves the purpose. I will then discuss three readings of the identity claim that can be formulated in light of such a distinction. I will conclude that even if the identity were to fail in any of the suggested readings, it would be possible to hold an account of fundamental powerful qualities.
\end{abstract}

\section{Powerful Qualities}

Dispositionality and qualitativity are key notions to describe the world that we inhabit. Dispositionality is a matter of what a thing is disposed to do in certain circumstances by virtue of having certain properties. A vase is disposed to shatter when struck by virtue of being fragile. An electron is disposed to exert and experience a force in accordance to Coulomb's Law when it interacts with other electrons by virtue of being negatively charged. A marble is disposed to resist acceleration when a force is applied on it by virtue of being massive. And so on. Loosely put, qualitativity is a matter of how a thing is like. There is no consensus on how to define this notion. As I shall understand it, a thing's qualitativity is a

Joaquim Giannotti

j.giannotti.1@ research.gla.ac.uk

1 Room 208, Department of Philosophy, University of Glasgow, Oakfield Avenue 69,

Glasgow G12 8LP, UK 
matter of its qualities (Strawson 2008, p. 278; Heil 2010, p. 70). In turn, a thing's qualities are actual properties that it possesses (Heil 2012, p. 59). Albeit contentious, examples of qualities are shape and colour properties such as that of being spherical and being cerulean.

In the interest of capturing adequately how things are, any satisfactory conception of fundamental properties ought to accommodate both dispositionality and qualitativity. Two conceptions reflect the distinction between these notions: dispositional properties and categorical ones.

Dispositional properties are essentially powerful. Namely, they essentially dispose their bearers to bring about a characteristic manifestation in a characteristic circumstance (Bird 2007a, p. 45). A classic example of a dispositional property is charge. In virtue of being charged, a particle is disposed to exert and experience an electric force when it interacts with other charged particles. Categorical properties are essentially qualitative: to have them is a matter of how a thing is like. For instance, having a distinctive arrangement of carbon atoms is a categorical property of a diamond; it is how the diamond is like. Call Dispositionalism the view that all fundamental properties are dispositional, or powers (Mumford 2006; Bird 2007a). Call Categoricalism the view that all fundamental properties are categorical, or qualities (Lewis 1986; Armstrong 1997). In contrast, mixed views hold that some fundamental properties are dispositional while others are categorical (Molnar 2003; Ellis 2001, 2002, 2012).

Some participants in the debate endorse the mutual exclusivity of dispositional and categorical properties. For example, Alexander Bird claims that "to say that a property is categorical is to deny that is necessarily dispositional" (2007a, pp. 66-67). Elsewhere, he says that "by definition, therefore, a property cannot be both a potency [power] and a categorical property [quality]" (Bird 2007b, p. 514). In similar vein, David Armstrong claims that categorical properties have a "nature that is self-contained, distinct from the powers that they bestow", while the nature of dispositional properties is "exhausted by the powers it bestow" (1997, p. 69). According to such a conception, qualities are non-dispositional properties.

Proponents of the powerful qualities view, whose leading representatives are Martin (1993a, 2008) and Heil (2003, 2012), believe that we need a conception of properties that does not bifurcate the dispositional and the qualitative in order to capture the world as we find it. The powerful qualities theorist disputes the mutual exclusivity of dispositionality and qualitativity. For example, Heil says that the categorical-dispositional distinction, "despite its comfortable familiarity, is deeply flawed" (Heil 2003, p. 118). Instead Martin claims that:

Dispositionality and qualitativity are correlative, complementary, inseparable, and covariant when they are displayed in their intrinsic and irreducible form at the level of the finer interstices of nature. (Martin 2008, p. 64).

The powerful qualities theorist conceives of qualities as actual properties of their bearers. For example, Heil takes qualities to be "here and now, actual, not merely potential, features of the objects of which they are qualities" (2012, p. 59). Elsewhere, he says the "ways things are are qualities" (Heil 2010, p. 70). In similar 
vein, Galen Strawson claims that "all being is categorical [i.e. qualitative] because that's what it is to be!" (Strawson 2008, p. 278). According to such a conception, to be a quality is to be an actual property of a bearer. For example, a vase's fragility is its disposition to shatter and also one of its actual properties. Therefore, the vases' fragility would be also a quality. A consequence of this conception is that every actual property is a quality. Yet we should not fear that this generates an unlovely proliferation of powerful qualities. The version of powerful qualities that I am considering is a doctrine about fundamental, or sparse properties. For present purposes, we can think of sparse properties as those whose sharing makes for objective similarities among things, they are highly specific, their classes or sets are not entirely miscellaneous and suffice to "characterise things completely and without redundancy" (Lewis 1986, p. 60). Sparse properties carve reality at its joints, so to speak. The powerful qualities theorist who endorses this version is not committed to the view that all actual properties are powerful qualities.

Two reasons motivate the powerful qualities view. First, at least some properties of our world appear to be both dispositional and qualitative in character. Consider mass and charge, two putative fundamental properties. In virtue of having a certain mass, a particle is disposed to generate a gravitational force. But having a certain mass is also a qualitative feature of a particle. By having a certain mass, a particle has a certain quantity of matter. This is a "here and now, actual, not merely potential" feature that particle has by virtue of possessing a certain mass (Heil 2012, p. 59). By being charged, a particle is disposed to produce an electromagnetic force. At the same time, by being charged, an object has a certain quantity of charge. This is a way that particle is occurrently by virtue of being charged.

Second, the powerful qualities theorist contends that both Dispositionalism and Categoricalism run into difficulties (Heil 2003, pp. 92-96, 102-105, 116-117). By contrast, the powerful qualities view escapes two standard objections against Dispositionalism and Categoricalism respectively. I will briefly illustrate these objections in what follows.

Let us consider firstly the standard objection against Dispositionalism. It is often argued that an ontology of nothing but pure powers, or purely dispositional properties lacks of sufficient actuality: particulars pass pure powers around and yet never take "a journey from potency to act" (Armstrong 1997, p. 80). This worry does not threaten the powerful qualities theorist. As I illustrated, the powerful qualities theorist thinks of the qualitative in terms of "here and now, actual, not merely potential" properties of an object (Heil 2012, p. 59). Thus a powerful quality empowers a bearer in a distinctive way and, simultaneously, is one of its actual properties.

Before illustrating the objection against Categoricalism, it is worth noting that the alleged superiority of the powerful qualities view with respect to Dispositionalism can be questioned. For example, Taylor (2018) argues that the dispositionalist could conceive of powers as actual properties in the same fashion of the powerful qualities theorist. This raises the question of whether there is a real distinction between the powerful qualities view and Dispositionalism. One might be worried that if both pure powers and powerful qualities are qualitative in the sense of being actual properties, then the powerful qualities view and Dispositionalism amount to the same view. An exhaustive discussion of this issue would require a separate investigation 
(see Taylor 2018 for a more detailed discussion). However, it is worth flagging that the powerful qualities theorist can argue that powerful qualities and pure powers are distinct kinds of property in spite of being both qualitative. It is the "dual nature" of a powerful quality that makes it dispositional and qualitative (Martin and Heil 1999, p. 46; Martin 2008, p. 45). In contrast, a pure power has a powerful but not qualitative nature. A pure power has qualitativity only derivatively, in virtue of its dispositional nature. Thus powerful qualities and pure powers appear to be distinct by virtue of having a different nature.

Now let us consider to the standard objection against Categoricalism. It is often argued that Dispositionalism is preferable over Categoricalism because the latter leads us to a troublesome commitment to "quidditism". In the literature, philosophers use "quidditism" and "quiddity" in different ways and mean different things with these terms. It is therefore unclear what quidditism entails. Here I take it to be the view that every property has an intrinsic non-dispositional feature that uniquely individuates it (Lewis 2009; Smith 2016, p. 251). ${ }^{1}$ An objection against quiddities so conceived is that they are unknowable. Our knowledge of properties is restricted to the roles they play, or occupy. Among these, there are dispositional roles as well. But it is one thing to know that a role is played and another is to know what property plays a certain role. It is one thing, for instance, to know that there is a property that plays the charge role. It is another thing to know what property plays the charge role. If what individuates a property is a non-dispositional quiddity, then knowledge of that property's dispositional role leaves us in the dark about its nature. While not everyone believe that this is a worrisome consequence (e.g. Lewis 2009), the powerful qualities theorist avoids this problem. Like the dispositionalist, she partly individuates (and therefore identifies) properties by their dispositionality. ${ }^{2}$

On the powerful qualities view, "every [fundamental] property of a concrete spatio-temporal object is simultaneously qualitative and dispositional", or a powerful quality (Heil 2003, p. 111). That is, all fundamental properties are powerful qualities (Martin 2008, p. 33, p. 64). In its canonical version, the powerful qualities view is committed to a distinctive identity claim between a property's dispositionality and its qualitativity. This version is known as the Identity Theory of powers (Heil 2003, p. 111). ${ }^{3}$

In the literature, the Identity Theory faces the charge of contradiction (Armstrong 2005, p. 315; Bird 2007b, p. 514; Barker 2013, p. 649). If the contradiction objection

\footnotetext{
${ }^{1}$ There is much discussion on whether we should posit quiddities, whether they are metaphysically distinct from their properties, and whether they exist. Those in favour of quiddities argue that we need to accept them because the dispositionality of a property does not warrant their individuation and identification. For an overview on quidditism, see Smith (2016).

${ }^{2}$ In a recent paper, Taylor (2018) argues that we can raise the property individuation objection against both Dispositionalism and the canonical version of powerful qualities. As it will become clear in due course, the powerful qualities theorist has a way to resist this objection.

${ }^{3}$ It is worth noting that Martin's early version of powerful qualities (1993a, 184; 1993b, p. 519) is a twosided view of properties. On this view, properties have a dispositional side and a qualitative one. By contrast, Heil $(2003,2010,2012)$ has always endorsed the identity claim between the dispositional and the qualitative. Martin abandons the two-sided view of powerful qualities and embraces the Identity Theory in his joint work with Heil (cf. Martin and Heil 1999, pp. 46-47). Martin (2008) is an identity theorist.
} 
is sound, it poses a fatal threat to the canonical version of powerful qualities view and its merits. We should therefore investigate whether the contradiction objection is sound and whether it is possible to articulate an alternative account of powerful qualities that is not committed to the identity claim between the dispositional and the qualitative. My aim in this paper is to show that it is possible to enjoy the benefits of the powerful qualities view without embracing the identity claim. To put it differently, I will show that there is room for an account of powerful qualities that is not committed to the identity between the dispositional and the qualitative. The plan is as follows. In the next section I will present more in detail the Identity Theory of powers (Sect. 2). To disambiguate it, I will propose a distinction between two senses of dispositionality and qualitativity (Sect. 3). I will then discuss three readings of the identity claim which is possible to formulate in light of such a distinction (Sect. 4). I will conclude that even if the identity claim were to fail in any of the proposed readings, it would be possible to adopt an account of fundamental powerful qualities.

\section{The Identity Theory of Powers}

A preliminary requirement for the Identity Theory is to abandon the mutual exclusivity of the categorical and the dispositional. A characterisation of the categorical, or qualitative as non-dispositional is a non-starter for it would render the Identity Theory contradictory (Armstrong 2005, p. 315). But the identity theorist does not conceive of the qualitative in opposition to the dispositional. The charge of contradiction is therefore avoided.

According to the powerful qualities theorist, qualitativity is a matter of the actual or occurrent properties of bearers (Strawson 2008, p. 278; Heil 2010, p. 70). For example, Heil says that "qualities are here and now, actual, not merely potential, features of the objects of which they are qualities" (2012, p. 59). This characterisation is not particularly informative, but it permits the identity between the dispositional and the qualitative. Note that a characterisation of qualities as non-dispositional does not offer any positive insight on their nature. Thus the question of whether it is possible to characterise qualitativity in a more informative way does not burden the identity theorist only; friends of Categoricalism face it as well.

Advocates of the powerful qualities view do not reject the categorical- dispositional distinction tout court. Rather they deflate it: the distinction between powers and qualities is held to be conceptual only. The identity theorist holds that the same property can be regarded as a power or quality in the same way in which the duckrabbit illustration can be regarded as a duck or rabbit (Heil 2003, pp. 119-120; Martin 2008, pp. 67-69).

The underlying idea of the analogy with the duck-rabbit illustration is that the different ways of considering a property do not demarcate a distinction in reality. Consider sphericality (the property of being spherical) for example. To consider sphericality dispositionally is to regard it as the power to roll on inclined planes that a spherical thing has. To consider sphericality qualitatively is to regard it as the distinctive and actual geometrical shape of a spherical thing. These ways of considering sphericality do not bear on its nature. 
Once we abandon the mutual exclusivity of the categorical and the dispositional, it is possible to hold that every fundamental property is a powerful quality; a property that is "at once dispositional and qualitative" (Martin and Heil 1999, p. 46).

It is tempting to think of a powerful quality as a 'compound' of qualitative and dispositional 'sides' (Heil 2003, p. 112; I will discuss the compound view of powerful qualities in Sect. 4). But this is not what the identity theorist has in mind: a powerful quality's dispositionality and its qualitativity are "identical with one another and with the unitary intrinsic property itself" (Martin 2008, p. 65). This claim, which I shall call Identity, has been formulated by Heil as follows (2003, p. 111).

Identity: a property $\mathrm{P}$ 's dispositionality, $\mathrm{Pd}$, is $\mathrm{P}$ 's qualitativity, $\mathrm{Pq}$, and each of these is $\mathrm{P}: \mathrm{Pd}=\mathrm{Pq}=\mathrm{P}$.

The commitment to Identity gives this version of the powerful qualities view the name of "Identity Theory" of powers. ${ }^{4}$

Before outlining its advantages, let me clarify how the Identity Theory can evade Taylor's objection (2018) that I mentioned in Sect. 1. A standard argument against Dispositionalism is that an ontology of only purely dispositional properties lacks the theoretical resources for property individuation (Lowe 2006, p. 138; 2010, 2012). There are various ways to spell out this argument (see Bird Bird 2007a, b, pp. 132-146). At heart, the individuation problem is as follows. A property's dispositionality cannot individuate such a property because its dispositionality is itself individuated by another property's dispositionality. For example, the disposition to shatter cannot individuate fragility because is itself individuated by the dispositionality of another property, such as that of having a certain crystalline structure. On Dispositionalism, the dispositionality of having a certain crystalline structure is individuated by another property's dispositionality. And so on, ad infinitum. Therefore, it appears that Dispositionalism faces a vicious regress. Taylor contends that the Identity Theory faces the same worry (2018, pp. 1345-1348). As such, it "confers no advantage" as compared to Dispositionalism with respect to the property individuation problem (Taylor 2018, p. 1437).

The identity theorist could attempt to escape the individuation problem by arguing that properties are partially individuated by their qualitativity (Heil 2012, pp. 73-75). However, Taylor argues that this strategy is illusory. On the Identity Theory, a property's dispositionality and its qualitativity are identical. Thus the individuation problem remains "as much of a problem" for the Identity Theory (Taylor 2018 , p. 1436). This is not to say that the property individuation problem forces us to abandon Dispositionalism or the Identity Theory. Advocates of both views can reject some premise of the individuation argument. For example, they can deny that a property is fully individuated by its dispositionality. However, there is a strategy that is available only to the identity theorist. Someone might argue that what individuates a property must be a qualitative feature of that property in virtue of which

\footnotetext{
${ }^{4}$ Others that adopted the Identity Theory are Strawson (2008), Jacobs (2011), Carruth (2016), Jaworski (2016) and Taylor (2013).
} 
it has a certain dispositionality (e.g. Smith 2016, pp. 249-251). ${ }^{5}$ For the argument's sake, let us suppose that this view is true. This would be bad news for the dispositionalist. If a property has a certain dispositionality in virtue of its qualitative nature, then we must abandon the central tenet of Dispositionalism, namely that a property's nature is dispositional. The identity theorist evades this problem. She can accept that the individuating feature of a property is a qualitative nature without renouncing the spirit of her view. Given Identity, such an individuating qualitative nature would be also dispositional. The resulting view appears to be compatible with the idea that it is the "dual nature" of a powerful quality that makes it at once dispositional and qualitative (Martin and Heil 1999, p. 46; Martin 2008, p. 45).

Of course, if the individuating qualitative feature were non-dispositional, both Dispositionalism and the Identity Theory would be incompatible with this view. Both Smith (2016) and Taylor (2018) acknowledge that on some views the individuating feature is indeed a non-dispositional nature. If the individuating feature were a non-dispositional nature, then Taylor would be right: the Identity Theory would not confer any advantage with respect to the property individuation problem (Taylor 2018 , p. 1437). Here I am considering a view according to which the qualitative and the dispositional are not understood in mutually exclusive terms (Smith 2016, pp. 249-251). In such a case, the identity theorist has no qualm in accommodating the idea that the individuating feature is a qualitative nature.

Now let us focus on Identity. The adoption of such a thesis has two specific merits. First, it ensures that the powerful qualities view does not amount to a conjunctive view of properties (Heil 2003, p. 119; Martin 2008, p. 63). Second, it distinguishes the Identity Theory from views according to which the dispositional is somehow grounded in the qualitative (Heil 2003, p. 112). A view of this sort is Prior, Pargetter, and Jackson's account of dispositionality (1982). According to them, powers are properties that objects have by possessing some qualitative property as their "casual basis" (Prior et al. 1982, pp. 252-253). For example, the causal basis of fragility is, for some objects, the qualitative property of having a certain crystalline structure. In contrast, on the Identity Theory, there is no "direction of priority or dependence" between dispositionality and qualitativity (Martin and Heil 1999, p. 47).

The commitment to Identity is the strongest way to tie together a property's dispositionality and its qualitativity. However, Identity does not elucidate the sense in which dispositionality and qualitativity are to be understood. The previous remarks hint at two different readings of these notions: one ontological, the other conceptual. According to an ontological reading, to say that that a property's dispositionality and its qualitativity are identical is to make a claim about that property's nature. According to a conceptual reading, Identity appears to be a claim about the dispositional and qualitative ways in which we can conceive of a property. The ontological reading and the conceptual one appear to be compatible. Here the suggestion is not that we must choose sides. Yet it would be greatly beneficial for the powerful

\footnotetext{
5 Of course, this strategy is a non-starter for both the dispositionalist and the identity theorist if the individuating feature is held to be non-dispositional (e.g. Lewis 2009; Barker 2009). Here I am considering a view according to which the individuating feature is qualitative and yet non-dispositional.
} 
qualities theorist to unpack Identity for at least two reasons. First, it improves the precision of the Identity Theory. Second, it reveals a number of interesting possibilities. The ontological and conceptual claims are distinct. It is therefore possible that some objections target one reading but not the other. It is also possible to formulate different versions of Identity Theory. Some of them could be committed to one claim instead of the other, while other versions to both. These are good reasons to examine further the idea of two senses of the notions of dispositionality and qualitativity. Thus I propose to take seriously a distinction between a conceptual sense and an ontological sense of dispositionality and qualitativity.

\section{Two Senses of Dispositionality and Qualitativity}

By adopting the distinction between two senses of dispositionality and qualitativity, we can reformulate Identity in a number of distinct ways. I shall concentrate on three

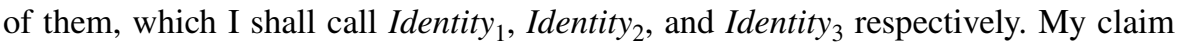
is not that these three readings exhaust all interpretative options. Yet Identity ${ }_{1}$ Identity $_{2}$, and Identity I $_{3}$ are well-suited to capturing the spirit of the Identity Theory.

In the conceptual sense, dispositionality and qualitativity can be regarded as ways of considering a property. In this sense, they are "different ways of presenting the selfsame property" (Martin and Heil 1999, p. 47), or "the selfsame property differently regarded" (Heil 2003, p. 112). There are at least two related ways of spelling out the idea of "ways of considering a property", which I shall formulate as Identity and Identity $_{2}$.

Identity $_{1}$ : the dispositional way of conceptualizing a property $\mathrm{P}$ and the qualitative way of conceptualizing $\mathrm{P}$ are ways of conceptualizing one and the same property $\mathrm{P}$.

Identity $_{2}$ : the dispositional description of a property $\mathrm{P}$ and the qualitative description $\mathrm{P}$ denote one and the same property $\mathrm{P}$.

In Identity ${ }_{1}$, the ways of considering a property are to be understood as ways of conceptualizing a property, or "modes of consideration" (Heil 2003, p. 119). This is the sense in which we can conceive of sphericality, for example, as a power or quality. The identity theorist appeals to the Lockean notion of partial consideration for clarifying this idea. To partially consider a property is to selectively regard it according to its dispositionality while ignoring its qualitativity or the other way round. The identity between the dispositional and qualitative ways of conceptualizing a property and the property itself has to be understood in the sense that these are ways of conceptualizing one and the same property (Martin and Heil 1999, p. 47). Someone might find this identity surprising. But the identity theorist would claim that such an identity is no more surprising than the identity between the duck and the rabbit in the duck-rabbit ambiguous figure.

Identity $_{2}$ can be regarded as the linguistic counterpart of Identity $_{1}$. Here the ways of considering a property are dispositional and qualitative descriptions of that property. Plausibly, a dispositional description of a property involves overt dispositional locutions or predicates such as "is disposed to ... when ..." or "has the disposition 
to ... when ..." (Bird 2007a, p. 20). However, a dispositional description of a property may involve also covert dispositional predicates or locutions, namely terms that do not explicitly refer to a disposition and its manifestation. An example of a covert dispositional term is "fragility", which corresponds to the "disposition to shatter when struck" (ibid.). In contrast, we can think of a qualitative description as one that does not involve covert or overt dispositional locutions. For example, a dispositional description of a diamond's hardness is "the diamond's disposition to scratch glass when raked across its surface"; a qualitative description is "the diamond's tetrahedral arrangement of carbon atoms" (cf. Jaworski 2016, p. 54). The identity between dispositional and qualitative descriptions with the property is analogous to the identity between "The Morning Star" and "The Evening Star" with the planet Venus. In the sense of Identity $_{2}$, dispositionality and qualitativity are different descriptions which denote one and the same property.

In the ontological sense, and to move towards an understanding of Identity ${ }_{3}$, dispositionality and qualitativity are ways of being of properties. In this sense, a property's dispositionality and its qualitativity "must be thought of as unrealizable limits for different ways of being of that property" (Martin and Heil 1999, pp. 46-47).

The notion of a way of being of a property is hard to characterise and appears to be conceptually primitive. Yet it conveys effectively the ontological sense of dispositionality and qualitativity. The ways of being of a property are ways that property is (Levinson 1978).

To elucidate the ontological sense of dispositionality and qualitativity, I introduce the notion of an aspect. According to this proposal, ways of being of properties are best understood as aspects of properties [this understanding is hinted at by Martin (1993a, b); but it can be found also in later works such as Martin and Heil (1999) and Martin (2008)]. Unfortunately, the term "aspect" creates an inevitable ambiguity. It gives the impression that properties are made of aspects in the same fashion in which wholes are made of parts. But this conception would violate the Identity Theory. Thus we need to specify some qualifications.

A property's aspects are the varied ways in which "it goes about the complicated business of existing" (Levinson 1978, p. 2). To say that a property has certain aspects means that it exists in certain manners, or ways. Here a clarification is needed. On Heil's view, first-order properties are ways particular objects are (2003, 2012). Since aspects are ways of properties, someone might one wonder whether ways have ways. This would erroneously suggest that first-order properties bear other first-order properties. To escape the confusion, we must be mindful of a distinction between properties, whose bearers are particular objects, and aspects, whose bearers are first-order properties. In order to facilitate the discussion and help the reader, I will employ the terms "property" and "aspect".

By adopting a conception of aspects, we can legitimately answer the question "In what ways are two properties different?". An example will clarify the idea. An aspect of a dispositional property is to endow essentially its bearers with a particular power that is manifested in appropriate circumstances. This is a way a dispositional property is. In contrast, a non-dispositional property lacks this aspect. That is, essentially conferring upon a bearer a certain power is not a way that a non-dispositional property is. 
There are various ways to interpret the claim that a property has aspects. For example, one might think of P's aspects as partial considerations of P. But this could generate a confusion between the mental act of partially considering a property and what is abstracted, namely a way of being of that property. Someone else might believe that aspects stand to properties in the same way that parts stand to a whole. As I will explain in this section, such a view clashes with the commitments of the identity theorist. The conception of aspects under scrutiny has four relevant qualifications, which I shall address in turn.

First, the nature of a property determines its aspects. What aspects a property has depends on how that property is. For example, an aspect of charge is to dispose its bearers to exert and experience a force in accordance to Coulomb's Law. According to the proposed conception, that charge has such an aspect depends on its nature.

Second, we can consider an aspect of a property by means of abstraction. To consider a property's aspect is to abstract a way that property is. Here it is crucial to distinguish between the act of abstraction and what is abstracted. The former is a mental process that involves selectively attending to a specific aspect a property has. The latter is an aspect, namely a way a property is.

Third, the aspects of a property supervene upon it. The notion of supervenience in question captures the idea that if the aspects of a property $\mathrm{P}$ supervene on $\mathrm{P}$, then it is impossible that $\mathrm{P}$ exists and P's aspects does not exist. The underlying idea is that once we have a property, we get its ways of being. Here I embrace the standard view that what supervenes is no addition to being (cf. Armstrong 1997, p. 12). Accordingly, the aspects of a property do not constitute a genuine addition to being with respect to the property of which they are aspects. I acknowledge that someone might favour an ontologically robust conception of aspects. Taylor (2018) offers an example of such a view. I will compare the proposed lightweight conception of aspects and Taylor's view in Sect. 4.

Fourth, the aspects of a property are modally fixed. In every possible world, for every property $\mathrm{P}$, a change in P's nature would determine a change in P's aspects. The modal fixity of aspects derives from their conception as ways properties are. Someone might prefer a conception according to which aspects can modally vary. This is an available option. Here it is not possible to adjudicate between these views. The choice rests on independent factors that cannot be adequately addressed in this paper.

On the proposed view, that properties have aspects does not entail that they are complex, structured entities: a property can be a simple, structure-less entity and yet have aspects (in the previous sense). An analogy will elucidate this point. Consider the standard view of tropes (Williams 1953; Campbell 1990; Simons 1994; Maurin 2002; Hakkarainen and Keinänen 2017). According to it, some tropes are mereologically simple entities that lack any constituents. Yet these simple tropes are individually distinct from each other and primitively resembling to some other ones. These features are not additional entities that simple tropes have. Rather, according to the standard view, they supervene on simple tropes. Thus a simple trope's features are "pseudo-additions" for what supervenes do not constitute an addition to being (Campbell 1990, p. 37). To use a metaphor, God's creation of a simple trope $\mathrm{T}$ suffices for $\mathrm{T}$ being distinct from any other tropes and $\mathrm{T}$ being primitively 
resembling to some other tropes. Like simple tropes' features, aspects supervene on properties and describe how properties exist. Of course, the standard view of tropes is not exempt from problems (e.g. Daly 1994). For reasons of space, I will not discuss them here. A word of caution: the proposed conception of aspects does not require deciding between tropes or universals. This choice rests on independent reasons related to costs and benefits of these conceptions.

It is worth acknowledging that we could conceive of aspects in different ways. For example, someone could think of them as processes or series of events things go about existing. According to such a conception, the dispositionality and qualitativity of a property could be regarded as two processes it can undergo. The identity claim between a property's dispositionality and its qualitativity would concern the identity of such processes. This is an available view. However, such an interpretation of the Identity Theory is not suggested by its proponents. Therefore, I will not explore a process version of the Identity Theory.

To repeat, the qualifications of the proposed conception of aspects are as follows: (1) the nature of a property determines its aspects; (2) aspects can be considered in abstraction; (3) aspects are not ontological additions with respect to the properties of which they are aspects; and (4) aspects are modally fixed. These qualifications are crucial. The Identity Theory is not the view that "every property has a dispositional aspect and a qualitative aspect" (Heil 2003, p. 119), where aspects are ontic higherorder properties (Engelhard 2010 offers an example of this view). Nor is it the view that powerful qualities are "two-part compound" properties (Martin 2008, p. 64; cf. Taylor 2018; I will discuss a compound view of powerful qualities in the next section). A 'compound' conception of this sort violates the Identity Theory. First, it reiterates the bifurcation between dispositional and categorical properties that the identity theorist rejects. Second, it treats powerful qualities as conjunctive properties of some sort (Heil 2003, pp. 118-120).

Fortunately, the previous objections do not target the proposed conception of aspects. It is worth stressing this point: the claim that a property has dispositional and qualitative aspects does not reiterate an ontologically robust distinction between dispositional and categorical properties. Nor does it entail that a property with dispositional and qualitative aspects is conjunctive. It is therefore possible to reformulate the powerful qualities view in terms of aspects.

Before proceeding any further, let us consider an example to clarify the idea of aspects. The property of having a certain charge disposes a particular $x$ to generate electromagnetic fields. Disposing $x$ to generate electromagnetic fields is an aspect of having a certain charge; it is a way the property of having a certain charge is. We can consider this aspect in abstraction from other aspects of the property of having a certain charge such as that of disposing $x$ to exert a force in accordance to Coulomb's law. Once you have the property of having a certain charge, you get its aspects of disposing a bearer to generate electromagnetic fields and exerting a force in accordance to Coulomb's law. These aspects supervene on the property of having a certain charge. Therefore, they do not constitute a genuine addition to being. Lastly, these aspects are modally fixed: in every possible world where the property of having a certain charge exists, it has the aspects of disposing a bearer to generate electromagnetic fields and exerting a force in accordance to Coulomb's law. 
In accordance to this proposal, it is possible to reformulate the powerful qualities view as the view that every fundamental property has dispositional and qualitative aspects. Note that this is a claim about the kind of aspects that fundamental properties have, not their number.

The notion of a dispositional aspect is meant to capture the core idea of dispositionality. Namely, that by having a certain property a bearer possesses some powers or dispositions that are manifested in appropriate circumstances. I propose that if a property $\mathrm{P}$ has some dispositional aspects, then there is a power or cluster of powers that is possessed by every bearer of P. For present purposes, we do not need to adjudicate the question whether powerful qualities are multi-track or single-track. Namely, we do not need to decide whether the possession of a powerful quality confers upon a bearer only one power or more (for a more detailed discussion on multi-track powers, see: Bird 2007a, pp. 21-24; Williams 2011; Vetter 2013). An example will elucidate the notion of a dispositional aspect. Consider the property of having a certain gravitational mass. By having a certain gravitational mass, a particle has the power to produce a gravitational force. This is a dispositional aspect of having a certain gravitational mass. Note that the proposed formulation is not a reductive analysis of dispositionality. Rather it aims to clarify the relation between the dispositional aspects of a property and powers, which are ascribed to individuals.

The notion of a qualitative aspect captures the idea that the possession of certain actual properties contributes to how a bearer is like (Heil 2010, p. 70, 2012, p. 59). We can say that the qualitative aspect of a property determines the occurrent makeup of a bearer of that property (Martin and Heil 1999, pp. 45-46). More precisely: if a property $\mathrm{P}$ has some qualitative aspects, then they qualitatively contribute to the make-up of every bearer of P. For example, consider the property of having a certain mass. By possessing this property, a particle has a certain quantity of matter. This is a qualitative contribution of the property of having a certain mass to that particle. Namely, having a certain quantity of matter is an actual way the particle is like by having a certain mass. As for the dispositional aspect, the notion of qualitative aspect is not a reductive analysis of qualitativity. One might worry that the proposed characterisation does not illuminate the idea of a qualitative aspect. Perhaps this is due to the generality of the notion of qualitativity. Here I acknowledge that someone might favour a characterisation of the qualitative aspect in opposition to the dispositional one. Accordingly, a property's qualitative aspect is one that does not contribute in any way to the dispositionality of a bearer of that property. For example, this is the conception offered by Taylor (2018, p. 1438) (I will discuss Taylor's view in more detail in the next section). While it remains an available option, this conception prevents the Identity Theory to take off the ground. If Identity concerns the identity between the dispositional and qualitative aspects of a property, and if the qualitative aspect is non-dispositional, then Identity is trivially false. In contrast, the proposed characterisation leaves open the possibility that a property's qualitative aspect is also dispositional. It is therefore a more promising option for making sense of the ontological sense of Identity. For example, it allows the possibility that mass' dispositional aspect of disposing a bearer to produce gravitational force is identical with its qualitative aspect of conferring upon a bearer a certain quantity of matter. I 
will discuss the plausibility of the identity claim between dispositional and qualitative aspects in Sect. 4.

The proposed characterisation of a qualitative aspect is available to anyone who embraces the proposed conception of qualitativity. For example, the dispositionalist who maintains that properties such as mass and charge are essentially dispositional, or "pure powers" can hold that they have qualitative aspects. Arguably, any serious pure powers theorist accepts that having a certain charge and having a certain mass contribute to the actual make-up of a particle. Yet it is still possible to distinguish between the Identity Theory and a pure powers view. On both views, all fundamental properties may have dispositional and qualitative aspects. But only powerful qualities have a dual "dispositional-cum-qualitative" nature (Martin and Heil 1999, pp. 45-46; Martin 2008, pp. 45-146). Someone might worry that if both pure powers and powerful qualities have dispositional and qualitative aspects, then it is unclear how to understand the alleged purity of powers. Here I would side with those who express their perplexity. However, a discussion of the purity of powers would be the topic of a separate investigation.

Now let us return to Identity. Having characterised the notions of dispositional and qualitative aspects, we can reformulate the ontological sense of Identity as follows:

Identity $_{3}$ : there is no real distinction between a property P's dispositional aspect and P's qualitative aspect, and each of these aspects belongs to one and the same property $\mathrm{P}$.

Identity $_{3}$ is somewhat different from the original Identity. The identity relation in Identity is numerical (Heil 2003, p. 111). But we cannot maintain numerical identity in Identity $_{3}$. Aspects are not any kind of entities. Therefore, they cannot be the relata of the standard numerical identity relation. If the identity theorist were to hold a

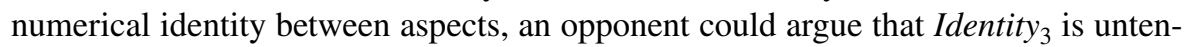
able. In order to make Identity 3 plausible, we must amend the relation between the dispositional aspect and the qualitative one. Here various options emerge. One way to capture the spirit of the original Identity claim is to say that there is no real, ontologically robust distinction between a property's dispositional aspect and its qualitative one. This interpretation captures the identity theorist's claim that a property's dispositionality and its qualitativity are not ontic, ontologically robust higher-order properties (Heil 2003, pp. 118-119). An example will clarify. Consider the property of having a certain mass. According to Identity $_{3}$, the dispositional aspect of disposing a bearer to produce a certain gravitational force is not really distinct from the aspect of conferring upon a bearer a certain quantity of matter. Presumably, the advocate of Identity 3 would argue that distinction between these aspects of mass is in thought only and, as such, it does not demarcate a distinction in reality. The advocate of Identity $_{3}$ could claim that the distinction between aspects is a matter of considering differently the ways of being of one and the same unitary property (I shall discuss the plausibility of the identity between aspects in the next section).

The second part of Identity $_{3}$ concerns the relation between the aspects of a property and the property itself. Also in this case, the plausibility of Identity 3 requires us to amend the numerical identity between the aspects and the property itself. Here 
we have various options. To preserve the spirit of the Identity Theory, we could

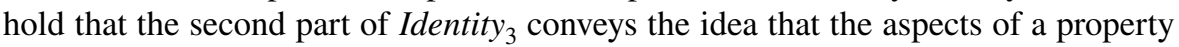
are dispositional and qualitative ways of being that belong to a single and unitary property. Such an interpretation captures the identity theorist's claim that a powerful quality is not a conjunctive property of some sort (cf. Heil 2003, pp. 118-119).

Inspection of Identity reveals three distinct claims: Identity ${ }_{1}$ and Identity I $_{2}$ are conceptual claims about the ways we can consider properties; Identity ${ }_{3}$ is an ontological claim about the nature, or ways of being, of properties.

\section{Toward a Dual-Aspect Account of Powerful Qualities}

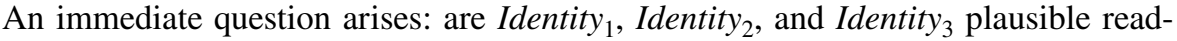
ings of Identity? In this section I will argue that even if they were not, we would not be forced to abandon the powerful qualities view tout court. However, my claim is not that if Identity $_{1}$, Identity , and Identity $_{3}$ are false or ill-suited to capturing the distinctive claim identity theorists wished to make, then Identity should be rejected. I acknowledge the possibility of other readings of Identity. Recall that my aim is not to show that the falsity of the Identity Theory, but that we can articulate an account of powerful qualities that is not committed to any of the suggested readings of Identity. My claim is therefore conditional: if Identity $_{1}$ Identity $_{2}$, and Identity Id $_{3}$ were false, it would be still possible to hold an account of fundamental powerful qualities. Aspects elucidate such a possibility. According to the proposed conception, aspects can do some metaphysical work without requiring any cost to be paid by the coin of ontology. Namely, aspects allow us to account for the relation between having a property and the possession of certain powers or qualities in terms of that property's ways of being. However, the proposed view of aspects is only one among many. For example, someone might favour an ontologically robust conception of aspects. An example is Taylor's compound view, according to which powerful qualities are "essentially compounds of distinct dispositional and qualitative parts" (2018, p. 1438). Toward the end of this section, I will briefly compare the relative costs and merits of Taylor's compound view and the proposed framework. As I will explain, both views are on a par with respect to the task of distinguishing powerful qualities from pure powers and categorical properties. Yet the proposed conception of aspects may be preferable over Taylor's one for its parsimony. But let us proceed with order.

To begin with, let us focus on the plausibility of Identity Ind Identity $_{2}$. Both readings involve a conceptual sense of dispositionality and qualitativity. This warrants a unified treatment. One could argue that these claims are conceptual and therefore compatible with ontological views that privilege either the dispositional over the qualitative or the other way round. An example of this view is Prior, Pargetter and Jackson's account of dispositionality (1982) already mentioned (Sect. 2). Such a possibility undermines the identity theorist's commitment to the claim that dispositionality and qualitativity are "equally basic" and there is "no direction of dependence or priority" among them (Martin and Heil 1999, p. 46). For example, suppose that charge's dispositionality is a description or way of conceptualizing charge in terms of overt or covert dispositional predicates such as "has the disposition to exert and 
experience a force in accordance to Coulomb's Law" (cf. Bird 2007a, b, pp. 19-20). In contrast, suppose that charge's qualitativity is a description or way of conceptualizing charge that does not refer to overt or covert dispositional locutions such as "has a certain quantity of coulombs". Someone can maintain that these descriptions or ways of conceptualizing denote one and the same property of charge and yet hold that charge's dispositionality depends on its qualitativity. Relatedly, Identity ${ }_{1}$ and Identity $_{2}$ are neutral with respect to the nature of fundamental properties. On either reading, the Identity Theory turns out to be explanatorily weaker than Dispositionalism and Categoricalism. Albeit contentious, the latter offer an informative account of the nature of fundamental properties (Sect. 1). According to Dispositionalism, the nature of fundamental properties is dispositional. According to Categoricalism, it is qualitative. In order to capture the commitments of the identity theorist, an ontological reading of Identity is required.

Identity $_{3}$ appears to be a more promising option. This reading captures the ontological sense of dispositionality and qualitativity in terms of aspects of properties. Recall that the notion of a dispositional aspect captures the core idea of dispositionality, which is a matter of the powers a thing has by virtue of having a certain property. The notion of a qualitative aspect conveys the core idea of qualitativity, which is a matter of how a thing is like by virtue of having some actual property (Sect. 3).

However, also Identity 3 faces some objections. A possible argument against it goes as follows. By virtue of a property P's dispositional aspect, there is a power or cluster of powers that every bearer of $\mathrm{P}$ possesses. In contrast, there is no power or cluster of powers that every bearer of $\mathrm{P}$ possesses by virtue of P's qualitative aspect. Therefore, dispositional and qualitative aspects are distinct. An example will illustrate this argument. Suppose that the property of having a certain mass is a powerful quality. By virtue of the dispositional aspect of having a certain mass, a particle has the power to generate a gravitational force. In contrast, there is no power that the particle has by virtue of a qualitative aspect of mass such as that of having a certain quantity of matter. The opponent of Identity 3 would claim that this is just a qualitative contribution of the property of having a certain mass to the occurrent make-up of the particle.

The argument against Identity $_{3}$ seems to be compelling. However, the identity theorist could respond, for example, that the distinction between these aspects exists in thought only. As such, having a certain quantity of matter is not really distinct from the aspect of disposing a bearer to generate gravitational force. To my knowledge, no identity theorist has explicitly advocated Identity I $_{3}$ It is therefore unclear whether the identity theorist would adopt this strategy to resist the objection against Identity $_{3}$. Since it is not my aim to show the falsity of Identity ${ }_{3}$, I concede that there might be a way to salvage the claim that there is no real distinction between a property's dispositional aspect and its qualitative one. ${ }^{6}$

\footnotetext{
${ }^{6}$ Someone who thinks that the dispositionality and qualitativity of a property are processes might argue that Identity $_{3}$ is true in the sense that one and the same property can undergo two processes at the same time.
} 
It is worth repeating that my aim in this paper is to show that it is possible to articulate an account of powerful qualities that is not committed to any of the suggested readings of Identity. The claim here is conditional: if each of the proposed readings of Identity were fail, it would be still possible to endorse an account of fundamental powerful qualities. This is good news for those who think that the previous argument establishes the implausibility of Identity $_{3}$.

It is worth noting that the identity theorist could resist the previous objections against Identity $_{1}$ Identity $_{2}$, and Identity 3 by claiming that the opponent failed to understand Identity. This strategy is always available, but not particularly illuminating. So let us suppose, for the sake of the argument, that the opponent is right;

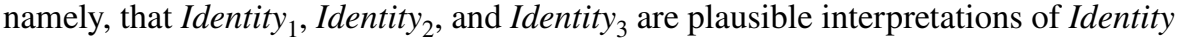
but ill suited for its tenability. Shall we abandon the powerful qualities view? It does not seem so. The introduction of dispositional and qualitative aspects paves the way toward a novel account that renounces Identity.

The powerful qualities view can be understood as committed to the claim that every fundamental property has essentially dispositional and qualitative aspects (Sect. 3). This is an ontological thesis about the ways fundamental properties are. By contrast, Identity I $_{1}$ and Identity I $_{2}$ are conceptual claims about the ways in which we can think of properties. These claims are clearly independent: one can endorse the powerful qualities view embracing neither Identity nor Identity $_{2}$. So if Identity

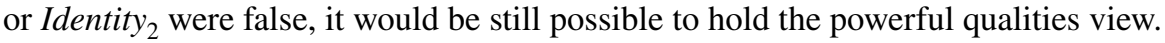

Now let us consider Identity ${ }_{3}$, which states that there is no real distinction between a property's dispositional aspect and its qualitative one. The view that every fundamental property has dispositional and qualitative aspects does not depend on Iden$t_{i t y}$. It is possible to maintain that every fundamental property has dispositional and qualitative aspects without being committed the view that there is no real distinction between them. Even if we abandon Identity $_{3}$, the resulting view is in the ballpark of the Identity Theory: every fundamental property has dispositional and qualitative aspects; these are aspects of one and "the same unitary property" (Martin 2008, p. 63). Overall, it is therefore possible to preserve the powerful qualities view and its merits independently of whether Identity holds in any of the suggested readings. To put it differently, the introduction of aspects allows us to maintain that every fundamental property has dispositional and qualitative aspects without being committed to any of the proposed versions of Identity. I argued that there are at least three advantages for favouring this approach. First, the introduction of aspects improves the precision of the Identity Theory. Second, and relatedly, it evades the charge of contradiction. Third, it clears the way toward a novel account of powerful qualities which has two significant merits: (1) it escapes the objections against the proposed interpretations of Identity; (2) it clarifies the ontological commitment of the powerful qualities view.

According to the proposed framework, aspects are ways properties are. By being supervenient on properties, they do not constitute a genuine addition to being (Sect. 3). One might wonder whether there is any reason for favouring an ontologically robust conception of aspects. An example of such a view is offered by Taylor (2018, pp. 1438-1439). Taylor proposes a compound view of powerful qualities as a middle ground between Categoricalism and a pure powers view. On Taylor's 
compound view, properties are "essentially compounds of distinct dispositional and qualitative parts” (Taylor 2018, p. 1438). These 'parts' can be regarded as the ontologically heavyweight counterpart of aspects. The dispositional parts of a property contribute to the dispositions a bearer in some ways. In contrast, the qualitative parts are those that do not contribute to the dispositions of a bearer (ibid.). While its adoption presupposes the rejection of Identity, the compound view has two important advantages: first, it is clearly different from a pure powers view; second, it is distinct from Categoricalism as traditionally understood (Taylor 2018, pp. 1438-1439). The first merit has to do with Taylor's claim that the Identity Theory and the pure powers view fail to be distinct. According to Taylor, "neither position can claim an advantage over the other" for both views have access to the same theoretical resources (2018, p. 1438). The second merit concerns the idea that properties, on the compound view, have their dispositional and qualitative parts (or aspects) essentially. In contrast, the categoricalist maintains that the dispositional contributions the possession of a property makes to its bearer are not essential to it. Thus the compound view is different from Categoricalism. Here I shall not discuss whether Taylor is right in thinking that the Identity Theory and the pure powers view fail to be distinct. Instead I shall concentrate on the question of whether there is any reason for favouring an ontologically lightweight conception of aspects over the compound view.

Call dual aspect account the view according to which properties have essentially dispositional and qualitative aspects thought of as in accordance to the proposed characterisation in Sect. 3. Like the compound view, the dual aspect account is distinct from both the pure powers view and Categoricalism.

The dual aspect account can be distinguished from the pure powers view by considering the nature of properties. If Taylor is right, then also pure powers have dispositional and qualitative aspects. However, only on the dual aspect account properties have a dual, dispositional and qualitative nature (Martin and Heil 1999, pp. 44-45; Martin 2008, p. 44). In contrast, on the pure powers view, properties have only a dispositional, or powerful nature (e.g. Bird 2007a). The qualitativity of pure powers is only derivative. In same vein, the dual aspect account can be distinguished from Categoricalism. On the latter, the nature of properties is qualitative in the sense of being non-dispositional. The adoption of either the compound view or the dual aspect account does not confer any significant advantage with respect to the task of distinguishing powerful qualities from pure powers view or categorical properties. In this respect, the compound view and a dual aspect account are on a par. However, it seems to me that there are at least two reasons for favouring the latter over the former.

First, the dual aspect account does not force us to embrace a characterisation of qualitative aspects in opposition to the dispositional ones (cf. Taylor 2018, p. 1438). Therefore, we evade an unlovely negative characterisation of qualitativity. Consequently, the dual aspect account preserves the spirit of the powerful qualities view. Recall that according to the powerful qualities theorist, the mutual exclusivity of the dispositional and the qualitative is "deeply flawed" (Heil 2003, p. 118).

Second, the dual aspect account is more parsimonious than the compound view. From the viewpoint of the dual aspect account, aspects are no addition to being with respect to the properties of which they are aspects (Sect. 3). In contrast, on 
the compound view, the dispositional and qualitative parts are ontologically robust aspects. A more precise assessment of these views will require further work. Both the dual aspect theorist and the advocate of the compound view must provide a rigorous characterisation of the relation between aspects and properties. This would be the task for a separate investigation. For present purposes, it suffice to note that the ontological parsimony of a dual aspect account represents yet another merit of the proposed conception of powerful qualities. Overall, the introduction of aspects is beneficial for it allows us: (1) to make the Identity Theory more precise; (2) to evade the charge of contradiction against it; and (3) to pave the way toward a dual aspect account of powerful qualities, which is not committed to Identity and is more parsimonious than other options in the vicinity such as the compound view outlined by Taylor (2018).

\section{Conclusion}

The Identity Theory of powers is a serious contender among theories of fundamental properties. In its canonical version, however, it is committed to a controversial identity claim between the dispositionality and qualitativity of properties. In this paper, I showed that we could enjoy the benefits of the Identity Theory without embracing the identity between the dispositional and the qualitative. To accomplish this aim, I proposed a distinction between two senses of dispositionality and qualitativity: one conceptual, the other ontological. In light of such a distinction, I singled out three versions of the Identity Theory. I then argued that the conceptual versions fail to capture the ontological commitments of the identity theorist. The ontological version is more promising, but it faces a potential objection. Yet I contended that this objection does not threaten the powerful qualities theorist: I showed that there is room for an account of fundamental powerful qualities that is not committed to any of the suggested readings of the identity claim.

Open Access This article is distributed under the terms of the Creative Commons Attribution 4.0 International License (http://creativecommons.org/licenses/by/4.0/), which permits unrestricted use, distribution, and reproduction in any medium, provided you give appropriate credit to the original author(s) and the source, provide a link to the Creative Commons license, and indicate if changes were made.

\section{References}

Armstrong, D. (1997). A world of states of affairs. Cambridge: Cambridge University Press.

Armstrong, D. (2005). Four disputes about properties. Synthese, 144, 309-320.

Barker, S. (2009). Dispositional monism, relational constitution, and quiddities. Analysis, 69(2), 242-250.

Barker, S. (2013). The emperor's new metaphysics of powers. Mind, 112(487), 605-653.

Bird, A. (2007a). Nature's metaphysics. New York: Oxford University Press.

Bird, A. (2007b). The regress of pure powers? The Philosophical Quarterly, 57(229), 513-534.

Campbell, K. (1990). Abstract particulars. Oxford: Blackwell. 
Carruth, A. (2016). Powerful qualities, zombies and inconceivability. The Philosophical Quarterly, 66(206), 25-46.

Daly, C. (1994). Tropes. Proceedings of the Aristotelian Society, 94(1), 253-262.

Ellis, B. (2001). Scientific essentialism. Cambridge: Cambridge University Press.

Ellis, B. (2002). The philosophy of nature: A guide to the new essentialism. Chesham: Acumen.

Ellis, B. (2012). The categorical dimensions of the causal powers. In A. Bird, B. Ellis, \& H. Sankey (Eds.), Properties, powers and structures. New York: Routledge.

Engelhard, K. (2010). Categories and the ontology of powers: A vindication of the identity theory of properties. In A. Marmodoro (Ed.), The metaphysics of powers: Their grounding and their manifestations. New York: Routledge.

Hakkarainen, J., \& Keinänen, M. (2017). The ontological form of tropes. Philosophia, 45(2), 647-658.

Heil, J. (2003). From an ontological point of view. Oxford: Oxford University Press.

Heil, J. (2010). Powerful Qualities. In A. Marmodoro (Ed.), The metaphysics of powers: Their grounding and their manifestations. New York: Routledge.

Heil, J. (2012). The universe as we find it. Oxford: Oxford University Press.

Jacobs, J. (2011). Powerful qualities, not pure powers. The Monist, 94(1), 81-102.

Jaworski, W. (2016). Structure and the metaphysics of mind. New York: Oxford University Press.

Levinson, J. (1978). Properties and related entities. Philosophy and Phenomenological Research, 39(1), $1-22$.

Lewis, D. (1986). On the plurality of worlds. Oxford: Blackwell.

Lewis, D. (2009). Ramseyan humility. In D. Brandon-Mitchell \& R. Nola (Eds.), Conceptual analysis and philosophical naturalism. Cambridge: MIT Press.

Lowe, E. J. (2006). The four category ontology. Oxford: Oxford University Press.

Lowe, E. J. (2010). On the individuation of powers. In A. Marmodoro (Ed.), The metaphysics of powers: Their grounding and their manifestations. New York: Routledge.

Lowe, E. J. (2012). Asymmetrical dependence in individuation. In F. Correia \& B. Schneider (Eds.), Metaphysical grounding. Cambridge: Cambridge University Press.

Martin, C. B. (1993a). Power for realists. In J. Bacon, K. Campbell, \& L. Reinhardt (Eds.), Ontology, cause and mind: Essays in honour of D. M. Armstrong. Cambridge: Cambridge University Press.

Martin, C. B. (1993b). The need of ontology: Some choices. Philosophy: The Journal of the Royal Institute of Philosophy, 68(266), 502-522.

Martin, C. B. (2008). The mind in nature. Oxford: Oxford University Press.

Martin, C. B., \& Heil, J. (1999). The ontological turn. Midwest Studies in Philosophy, 23(1), 34-60.

Maurin, A.-S. (2002). If tropes. Dordrecht: Kluwer Academic Publishers.

Molnar, G. (2003). Powers. New York: Oxford University Press.

Mumford, S. (2006). The ungrounded argument. Synthese, 149, 471-489.

Prior, E., Pargetter, R., \& Jackson, F. (1982). Three theses about dispositions. American Philosophical Quarterly, 19(3), 251-257.

Simons, P. (1994). Particulars in particular clothing-Three trope theories of substance. Philosophy and Phenomenological Research, LIV, 3, 553-575.

Smith, D. (2016). Quid quidditism est? Erkenntnis, 81, 237-257.

Strawson, G. (2008). The identity of the categorical and the dispositional. Analysis, 68(4), 271-282.

Taylor, H. (2013). In defence of powerful qualities. Metaphysica, 14(1), 93-107.

Taylor, H. (2018). Powerful qualities and pure powers. Philosophical Studies, 175(6), 1423-1440.

Vetter, B. (2013). Multi-track dispositions. The Philosophical Quarterly, 63, 330-352.

Williams, D. C. (1953). On the elements of being I. Review of Metaphysics, 7, 3-18.

Williams, N. E. (2011). Putting powers back on multi-track. Philosophia, 39(3), 581-595.

Publisher's Note Springer Nature remains neutral with regard to jurisdictional claims in published maps and institutional affiliations. 